\title{
Correlação linear e espacial dos componentes de produção e produtividade da soja
}

\section{Linear and spatial correlation of the yield components and soybean yield}

\author{
Flávio Carlos Dalchiavon ${ }^{1 *}$; Morel de Passos e Carvalho
}

\section{Resumo}

A soja é a cultura de grãos mais cultivada no Brasil, com enorme importância socioeconômica. No ano agrícola de 2008/09, no município de Selvíria (MS), no Cerrado Brasileiro, foram analisados os componentes de produção e a produtividade da soja cultivada em Latossolo Vermelho distroférrico em sistema plantio direto. $\mathrm{O}$ objetivo foi selecionar entre os componentes de produção número de vagens por planta, número de grãos por vagem, número de grãos por planta, massa de mil grãos, massa de grãos por planta e população de plantas, aquele com a melhor correlação, linear e espacial, visando explicar a variabilidade da produtividade da soja. Foi instalada a malha geoestatística irregular, para a coleta de dados, com 120 pontos amostrais, numa área de 8,34 ha. Os valores dos alcances da dependência espacial a serem empregados deverão estar compreendidos entre 38,1 e 114,7 metros. O modelo dos semivariogramas ajustados foi predominantemente o esférico. Do ponto de vista linear e espacial, o número de vagens por planta e a massa de grãos por planta correlacionaram-se de forma direta com a produtividade da soja, demonstrando serem os melhores componentes para estimá-la.

Palavras-chave: Agricultura de precisão, geoestatística, Glycine Max, variabilidade espacial

\begin{abstract}
The soybean is the crop most cultivated in Brazil, with great socioeconomic importance. In the agriculture year 2008/09 in Selvíria County, Mato Grosso do Sul State, in the Brazilian Savannah, was analyzed the production components and the soybean yield cultivated in a Typic Acrustox on no-tillage. The main purpose objective was select among the production components number of pods per plant, number of grains per pod, number of grains per plant, mass of a thousand grains, mass of grains per plant and population of plants, which of the best linear and spatial correlation aiming explain the soybean yield variability. The irregular geostatistical grid was installed to collect of data, with 120 sampling points, in an area of 8.34 ha. The values of spatial dependence range to be utilized should be among 38.1 and 114.7 meters. The model of the adjusted semivariograma was predominantly the spherical. Of the lineal and spatial point of view, the number of pods per plant and the mass of grains per plant they were correlated in a direct way with the soybean yield, demonstrating be the best components to esteem her. Key words: Precision agriculture, geoestatistics, Glycine max, spatial variability
\end{abstract}

\footnotetext{
${ }^{1}$ Doutorando em Agronomia, Faculdade de Engenharia de Ilha Solteira, UNESP. Rua das Orquídeas, 276, Bairro Novo Diamantino, 78402-000, Diamantino, MT. E-mail: fcdalchiavon@hotmail.com

2 Prof. Livre-Docente do Dept ${ }^{\circ}$ de Fitossanidade, Engenharia Rural e Solos, Faculdade de Engenharia de Ilha Solteira, UNESP. E-mail: morel@agr.feis.unesp.br

* Autor para correspondência
} 


\section{Introdução}

A soja (Glycine max (L.) Merrill) é uma cultura de grande importância socioeconômica para o Brasil. De acordo com dados da Companhia Nacional de Abastecimento (2010), sua produção na safra 2009/10, totalizou 68,71 milhões de toneladas, sendo que a região Centro-Sul participou com $89,7 \%$ desta, ou seja, com 61,67 milhões de toneladas. A área cultivada com a leguminosa ocupou 23,36 milhões de hectares, com produtividade média nacional estimada de $2941 \mathrm{~kg} \mathrm{ha}^{-1}$.

O conhecimento da produtividade agrícola da soja pode ser obtido pelos seus componentes de produção. Conforme Navarro Júnior e Costa (2002), o número de vagens/planta e de grãos/ vagens são os dois componentes mais importantes da produtividade de grãos de soja, uma vez que alterações nesses componentes são responsáveis diretos pelo ajuste da produtividade, podendo ocorrer com a modificação na população de plantas. Entretanto, sabe-se que existe variabilidade em tais componentes entre indivíduos de uma população em função de vários fatores, que vão desde a implantação da cultura (influenciando o número de plantas por área), até a disponibilidade de assimilados (modificada pelo arranjo de plantas), que afetam os demais componentes (número de vagens/planta, número de grãos/vagem e a massa de grãos).

Para avaliar o comportamento espacial dos componentes de produção e da produtividade, o mais indicado é a utilização de técnicas geoestatísticas, que, por meio de semivariogramas, permitem definir o alcance e o grau da dependência espacial e fornecem parâmetros para a elaboração de mapas de variabilidade pela krigagem e/ou cokrigagem (FRASSON; MOLIN, 2006; ZANÃO JÚNIOR et al., 2010). O semivariograma é um gráfico que caracteriza a estrutura da variância do atributo estudado como variável regionalizada em função da distância no terreno. $\mathrm{O}$ alcance da dependência espacial é o principal parâmetro fornecido pela geoestatística, representando a distância dentro da qual os valores de um determinado atributo são iguais entre si. Por outro lado, a cokrigagem pode ser mais precisa do que a krigagem de um atributo simples quando o semivariograma cruzado apresentar dependência entre dois atributos quaisquer (TRANGMAR et al., 1985). Além do que, exclusivamente em relação à variável primária, que normalmente é sub-amostrada, essa técnica possibilita efetuar a estimativa dos seus valores não amostrados. Dessa forma, são estabelecidas as zonas específicas de manejo, condições necessárias à agricultura de precisão.

Neste sentido, é reconhecido o uso e a contribuição destas técnicas na identificação e mapeamento da variabilidade intrínseca aos componentes de produção dos cultivos agrícolas. Segundo Pires (2002), estas técnicas podem permitir avaliar a variabilidade espacial para características como produtividade e componentes da produção, bem como a ocorrência de padrões (manchas) de áreas de lavoura associadas, por exemplo, com espaço disponível por planta, ou, ainda, com componentes de produção (número de ramos produzidos, número de vagens por planta). Este tipo de estudo permite verificar, mesmo havendo diferenças entre plantas em determinados componentes relacionados à produtividade, se há possibilidade de se estabelecer áreas com comportamento similar, ou seja, se existe dependência espacial de outros componentes da soja, que não a produtividade de grãos comumente avaliada em nível de lavoura.

Desta forma, estudos têm demonstrado a importância de se conhecer a variabilidade espacial das culturas (SANTOS et al., 2006; MARTINS et al., 2009; ROSA FILHO et al., 2009; LIMA et al., 2010), cujo os alcances geoestatísticos para os trabalhos mencionados variaram entre 7,1 e 169,0 m. Contudo, a variabilidade espacial dos componentes de produção e sua correlação espacial com a produtividade de grãos têm sido pouco pesquisadas na cultura da soja. Neste sentido, o objetivo do presente trabalho foi analisar as correlações entre os componentes de produção e a variabilidade espacial da produtividade da cultura da soja. 


\section{Material e Métodos}

O experimento foi realizado na área experimental da Fazenda de Ensino e Pesquisa - Setor de Produção Vegetal, da Faculdade de Engenharia de Ilha Solteira (FEIS/UNESP), localizada no município de Selvíria (MS), entre as latitudes de $20^{\circ} 20^{\prime} 54^{\prime \prime}$ S e $20^{\circ} 21^{\prime} 03$ 'S, longitudes de $51^{\circ} 24^{\prime} 23^{\prime \prime} \mathrm{W}$ e $51^{\circ} 24^{\prime} 29^{\prime \prime} \mathrm{W}$, com a altitude média de $300 \mathrm{~m}$. O clima é classificado como $\mathrm{A}_{\mathrm{w}}$, segundo preceitos de Köppen, caracterizado como tropical úmido com estação chuvosa no verão e seca no inverno. Durante todo o ciclo da cultura, a precipitação pluvial, a umidade média diária relativa do ar e a temperatura média diária foram, respectivamente, de $746,4 \mathrm{~mm}, 80,5 \%$ e $25,9^{\circ} \mathrm{C}$. O solo no qual a malha experimental foi instalada é um LATOSSOLO VERMELHO DISTROFÉRRICO típico muito argiloso, A moderado (Typic Acrustox), com declive homogêneo de 0,055 $\mathrm{m} \mathrm{m}^{-1}$ (5,5\%) (EMBRAPA, 2006). No ano agrícola 1998/1999 o solo foi preparado com o arado de aiveca e, há onze anos vem sendo cultivado, no sistema plantio direto, com a seguinte rotação das culturas (1- soja, 2milho, e 3-algodão) sucedida das culturas invernais (1- aveia preta, 2- feijão, e 3- trigo).

A cultura da soja (Glycine max L. Merril) foi semeada no dia 02/12/2008 (cultivar BRS-68 Vencedora), cujo cultivo foi conduzido segundo as indicações técnicas para as principais culturas econômicas do Estado de São Paulo (FAHL et al., 1998). O espaçamento entre linhas foi de $0,45 \mathrm{~m}$, com uma população final de 16 plantas por metro na linha de semeadura. $\mathrm{Na}$ adubação de semeadura foram utilizados $300 \mathrm{~kg} \mathrm{ha}^{-1}$ da formulação 04-2020 (N-P-K).

Foram definidas as direções x e y do sistema de coordenadas cartesianas, num lançante estabelecido por três faixas de terraços agrícolas. Para tanto, foi utilizado, para o georrefenciamento dos pontos amostrais, um aparelho GPS com precisão de 1 a 3 metros. A área pesquisada compreendeu $83.421 \mathrm{~m}^{2}$ (8,34 ha), com as coordenadas cartesianas: $y=299$ $\mathrm{m}$ e $\mathrm{x}=279 \mathrm{~m}$, equivalendo às coordenadas UTM de latitudes 7.749.933 S-7.749.634 S e longitudes $457.645 \mathrm{~W}-457.366 \mathrm{~W}$.

Foram amostrados 120 pontos aleatoriamente, de forma que a distância entre eles ficasse homogeneamente distribuída, isto é, nem muito próximos e/ou muito distantes. Dessa forma, em média, cada ponto amostral ficou compreendido numa área de 695,18 m² (26,37 m x 26,37 m).

Os componentes de produção da soja pesquisados foram todos individualmente coletados no entorno de cada ponto amostral da malha experimental, tido como área útil. Em tal área, todos os 120 pontos foram alocados nas entrelinhas de semeadura, de forma que cada ponto ficasse no meio de duas delas $(0,90 \mathrm{~m})$. O comprimento de $1,00 \mathrm{~m}$ foi estabelecido no sentido de tais linhas. Assim, a área útil de cada ponto amostral foi de $0,90 \mathrm{~m}^{2}$. A colheita foi realizada em 01/04/2009. Foram avaliados: (a) produtividade de grãos de soja (PGO), (b) número de vagens por planta (NVP), (c) número de grãos por vagem $(\mathrm{NGV}),(\mathrm{d})$ número de grãos por planta (NGP), (e) massa de mil grãos (MMG), (f) massa de grãos por planta (MGP) e (g) população de plantas (POP).

Para as avaliações referentes aos componentes da produção, foram coletadas 10 plantas na área útil de cada ponto amostral, levando-as ao Laboratório de Análises de Sementes para realizar as seguintes determinações: NVP: obtido pelo número total de vagens/número total de plantas; NGV: obtido pelo número total de grãos/número total de vagens; NGP: obtido pelo número total de grãos/número total de plantas; MMG (g): determinada mediante coleta ao acaso e pesagem de uma amostra de 1000 grãos de cada uma das 120 parcelas amostrais; MGP (g): obtida pelo NGP x MMG/1000; POP: avaliada em campo contando-se as plantas em duas linhas de 1 metro cada, estimando-se o resultado em número de plantas por hectare; e a PGO: teve como área útil 2 linhas de semeadura por 1 metro de comprimento, onde as plantas foram colhidas e, após 
secagem, submetidas a trilha manual, e em seguida determinou-se a massa desses grãos, sendo os dados transformados em $\mathrm{kg} \mathrm{ha}^{-1}$ (13\% base úmida).

Para cada atributo estudado, efetuou-se a análise descritiva clássica, com auxílio do software estatístico SAS (SCHLOTZHAVER; LITTELL, 1997), em que foram calculados a média, a mediana, valores mínimos e máximos, o desvio-padrão, o coeficiente de variação, a curtose, a assimetria e a distribuição de freqüência. Posteriormente, realizou-se a identificação dos outliers, efetuando a substituição dos seus valores pelo valor médio dos circunvizinhos contidos na malha. Para testar a hipótese da normalidade, ou da lognormalidade, realizou-se o teste de Shapiro e Wilk (1965) a 5\%.

Foi montada a matriz de correlação de Pearson, objetivando efetuar as correlações lineares simples, com o Excel, para as combinações, duas a duas, entre todos os atributos estudados, a partir das quais foram efetuadas as modelagens das regressões lineares simples com a planilha de cálculos Excel. Por outro lado, utilizando-se o pacote computacional SAS, por intermédio do stepwise, a 10\% de probabilidade para a inclusão e exclusão de variáveis no modelo, foi efetuada a regressão linear múltipla da PGO (variável dependente) em função dos componentes de produção pesquisados (variáveis independentes) no intuito de selecionar aqueles atributos que, nos devidos casos, proporcionariam a melhor equação para estimar a PGO.

Isoladamente para cada atributo, foi analisada sua dependência espacial pelo cálculo do semivariograma simples. Entretanto, para aqueles que apresentaram interdependência espacial, calcularam-se também seus semivariogramas cruzados, com base nos pressupostos de estacionaridade da hipótese intrínseca pelo uso do pacote Gamma Design Software 7.0 (GS+, 2004). Os ajustes dos semivariogramas simples e cruzados, em função de seus modelos, foram efetuados prioritariamente pela seleção inicial de: (a) menor soma dos quadrados dos desvios (RSS); (b) maior coeficiente de determinação $\left(\mathrm{r}^{2}\right)$; e (c) maior avaliador da dependência espacial (ADE). A decisão final do modelo que representou o ajuste foi realizada pela validação cruzada, assim como para a definição do tamanho da vizinhança que proporcionou a melhor malha de krigagem e/ou cokrigagem, realizadas por meio da krigagem em blocos. Para cada atributo, foram relacionados o efeito pepita $(\mathrm{Co})$, o alcance (Ao) e o patamar $(\mathrm{Co}+\mathrm{C})$. A análise do avaliador da dependência espacial (ADE) foi realizada conforme sugestões de Cambardella, Moorman e Novak (1994), modificada pelo $\mathrm{GS}^{+}$(2004) conforme a seguinte expressão:

$$
\mathrm{ADE}=[\mathrm{C} /(\mathrm{C}+\mathrm{Co})] \cdot \mathbf{1 0 0}
$$

onde: ADE é oavaliador da dependência espacial; C é a variância estrutural; e C + Co é o patamar. A interpretação proposta para o ADE foi conforme a sugestão de Dalchiavon (2010), onde: a) ADE < $20 \%$ indicando variável espacial de dependência muito baixa (MB); b) $20 \% \leq \mathrm{ADE}<40 \%$ indicando variável espacial de dependência baixa (BA); c) $40 \% \leq \mathrm{ADE}<60 \%$ indicando variável espacial de dependência média (ME); d) $60 \% \leq \mathrm{ADE}<80 \%$ indicando variável espacial de dependência alta (AL), e e) $80 \% \leq \mathrm{ADE}<100 \%$ indicando variável espacial de dependência muito alta (MA).

\section{Resultados e Discussão}

Todos os atributos estudados, com exceção do $\mathrm{NGV}$, apresentaram distribuição de freqüência do tipo normal, sendo significativos a 5\% pelo teste da normalidade de Shapiro e Wilk (1965), uma vez que a variação da probabilidade esteve compreendida entre 0,117 e 0,832 (Tabela 1). Assim, os valores médios representarão as medidas de tendência central. A produtividade de grãos de soja (PGO) apresentou coeficiente de variação $(\mathrm{CV}=21,8 \%)$ alto (GOMES, 2000). O valor médio da PGO foi de 4639,4 kg ha-1, corroborando Costa e Thomas (2004), que relataram produtividade média de 4440 $\mathrm{kg} \mathrm{ha}^{-1}$, e Amado et al. (2007), com produtividades variando de $4430 \mathrm{~kg} \mathrm{ha}^{-1}$ a $4660 \mathrm{~kg} \mathrm{ha}^{-1}$. Por outro lado, a PGO foi bem superior às médias, todas no 
sistema plantio direto, de $3220 \mathrm{~kg} \mathrm{ha}^{-1}$ (FARACO, 2006); de $3380 \mathrm{~kg} \mathrm{ha}^{-1}$, em área de cerrado (SILVA et al., 2009) e de $3318 \mathrm{~kg} \mathrm{ha}^{-1}$ num Latossolo Vermelho distroférrico (ROSA FILHO et al., 2009), assim como, à média nacional de $2941 \mathrm{~kg} \mathrm{ha}^{-1}$ (CONAB, 2010).

Com relação aos componentes de produção (Tabela 1) número de vagens por planta (NVP), número de grãos por vagem $(\mathrm{NGV})$, número de grãos por planta (NGP), massa de mil grãos (MMG), massa de grãos por planta (MGP) e população de plantas (POP), os valores médios observados foram 72,2; 2,2; 157,6; 144,1 g; 23,0 g e 217500 plantas ha $^{-1}$, com CV de 25,0\% (alto), 8,6\% (baixo), 25,2\% (alto), 9,4\% (baixo), 28,7\% (alto) e 18,6\% (médio), respectivamente. Pires (2002), pesquisando o potencial produtivo da soja no Rio Grande do Sul em semeadura direta, obteve valores médios de 2,$2 ; 40,6 ; 181,0 \mathrm{~g}$ e $14,3 \mathrm{~g}$, com coeficientes de variação de 19,$0 ; 85,0 ; 29,0$ e $93 \%$ para os componentes de produção NGV, NVP, MMG e MGP, respectivamente, valores estes que, com exceção da MMG, foram inferiores aos resultados deste estudo.

Da mesma forma, Linzmeyer Junior (2006) relatou valores médios de 2,0 e 123,0 g para os componentes de produção $\mathrm{NGV}$ e $\mathrm{MMG}$, respectivamente, assim como Moreira, Leite e Prada Neto (2008), que também estudaram os componentes de produção NVP, NGV e MMG, e constataram valores médios de 52; 2,05 e 205,8 $\mathrm{g}$, respectivamente. A superioridade constatada pelo estudo realizado pelos últimos autores para o componente MMG, provavelmente deve-se a diferença genética do material utilizado. Contudo, os desempenhos dos componentes de produção garantiram a apreciável produtividade mencionada neste estudo (4639,4 $\left.\mathrm{kg} \mathrm{ha}^{-1}\right)$, em especial o NVP e a MGP (Tabela 1). Tais desempenhos foram resultantes do adequado suprimento hídriconutricional às plantas durante todo o seu ciclo fenológico.

De acordo com a Tabela 2, o teste de correlação de Pearson entre a PGO e os componentes de produção apresentou significância para os pares: 1) $\left.\mathrm{PGO} x \operatorname{NVP}\left(\mathrm{r}=0,651^{* *}\right), 2\right) \mathrm{PGO} \times \operatorname{NGP}(\mathrm{r}=$ $0,573 * *), 3)$ PGO x MMG (r=0,369**) e 4) PGO x $\operatorname{MGP}(\mathrm{r}=0,614 * *)$. Para estes pares, as correlações foram diretas, indicando que com o aumento do NVP, NGP, MMG e MGP, ocorrerá o aumento da produtividade de grãos de soja. Nota-se ainda que o NVP foi o componente de produção que mais contribuiu para a PGO $(\mathrm{r}=0,651 * *)$, conforme pôde ser verificado na Tabela 2. Assim, tais dados estão de acordo com o observado por CarpentieriPípolo, Gastaldi e Pipolo (2005).

Os modelos matemáticos $\mathrm{PGO}=\mathrm{f}(\mathrm{NVP}) \mathrm{e}$ PGO $=\mathrm{f}(\mathrm{MGP})$, que apresentaram os maiores coeficientes de correlação (Tabela 2), representados na Figura 1a,b foram respectivamente do tipo linear e potencial, com coeficientes de correlação (r) de $0,651 * *$ e $0,652 * *$ (Tabela 3 ). Com relação ao modelo matemático linear $\mathrm{PGO}=\mathrm{f}(\mathrm{NVP})$, o mesmo foi constatado por Didonet e Costa (2004) ao pesquisarem a cultura do feijoeiro.

Assim, pela aplicação da equação contida na Figura 1a, pode-se ressaltar que a PGO teve seus mais elevados valores (2833-4528 $\mathrm{kg} \mathrm{ha}^{-1}$ ) quando o NVP variou entre 72,2-118,7. Em contrapartida, os mais baixos valores (1276-2833 $\mathrm{kg} \mathrm{ha}^{-1}$ ) quando o NVP variou entre 29,5-72,2. Da mesma forma, explorando a equação contida na Figura $1 b$, pode-se observar que a PGO apresentou seus mais elevados valores (4627-6274 $\mathrm{kg} \mathrm{ha}^{-1}$ ) quando a MGP variou entre 23,0-43,1 g. Por outro lado, apresentou os mais baixos valores $\left(3164-4627 \mathrm{~kg} \mathrm{ha}^{-1}\right)$ quando o NVP variou entre 10,5-23,0 g. 
Tabela 1. Análise descritiva inicial dos componentes de produção e da produtividade de grãos de soja. Selvíria (MS), 2009.

\begin{tabular}{|c|c|c|c|c|c|c|c|c|c|c|}
\hline \multirow{3}{*}{ Atributos $^{(1)}$} & \multicolumn{10}{|c|}{ Medidas estatísticas descritivas } \\
\hline & \multirow{2}{*}{ Média } & \multirow{2}{*}{ Mediana } & \multicolumn{2}{|c|}{ Valor } & \multirow{2}{*}{$\begin{array}{l}\text { Desvio } \\
\text { Padrão }\end{array}$} & \multicolumn{3}{|c|}{ Coeficiente } & \multicolumn{2}{|c|}{$\begin{array}{l}\text { Probabilidade } \\
\text { do teste }\end{array}$} \\
\hline & & & Máximo & Mínimo & & $\begin{array}{c}\text { Variação } \\
(\%)\end{array}$ & Curtose & Assimetria & $\operatorname{Pr}<\mathbf{W}$ & DF \\
\hline PGO $\left(\mathrm{kg} \mathrm{ha}^{-1}\right)$ & $4.639,4$ & $4.568,9$ & $8.303,3$ & $2.250,4$ & $1.010,030$ & 21,8 & 0,870 & 0,464 & 0,148 & NO \\
\hline NVP & 72,2 & 70,9 & 118,7 & 29,5 & 18,037 & 25,0 & $-0,290$ & 0,180 & 0,832 & NO \\
\hline NGV & 2,2 & 2,2 & 2,7 & 1,8 & 0,189 & 8,6 & 0,448 & $-0,149$ & 0,133 & $\mathrm{LN}$ \\
\hline NGP & 157,6 & 156,9 & 264,9 & 66,1 & 39,703 & 25,2 & 0,172 & 0,202 & 0,590 & NO \\
\hline MMG (g) & 144,1 & 143,9 & 182,7 & 113,0 & 13,478 & 9,4 & 0,206 & 0,244 & 0,601 & $\mathrm{NO}$ \\
\hline MGP (g) & 23,0 & 22,9 & 43,1 & 10,5 & 6,595 & 28,7 & $-0,113$ & 0,359 & 0,117 & NO \\
\hline POP & $217.500,0$ & $211.111,1$ & $322.222,0$ & $133.333,0$ & $38.318,8$ & 17,6 & $-0,210$ & 0,279 & 0,128 & NO \\
\hline
\end{tabular}

(1) $\mathrm{PGO}=$ produtividade de grãos de soja, $\mathrm{NVP}=$ número de vargens por planta, $\mathrm{NGV}=$ número de grãos por vagem, $\mathrm{NGP}=$ número de grãos por planta, $\mathrm{MMG}=$ massa de mil grãos, $\mathrm{MGP}=$ massa de grãos por planta e $\mathrm{POP}=$ população de plantas; ${ }^{(2)} \mathrm{Pr}<\mathrm{W}=$ teste de normalidade Shapiro e Wilk; DF = distribuição de freqüência, sendo NO e LN respectivamente do tipo normal e lognormal.

Fonte: Elaboração dos autores.

Tabela 2. Matriz de correlação linear simples entre a produtividade de grãos de soja e os componentes de produção. Selvíria (MS), 2009.

\begin{tabular}{lcccccc}
\hline \multirow{2}{*}{ Atributos $^{(1)}$} & \multicolumn{5}{c}{ Coeficiente de correlação ${ }^{(2)}$} \\
\cline { 2 - 6 } & PGO & NVP & NGV & NGP & MMG & MGP \\
\hline NVP & $\mathbf{0 , 6 5 1 * *}$ & & & & \\
NGV & $-0,065$ & $\mathbf{- 0 , 2 0 5 *}$ & & & \\
NGP & $\mathbf{0 , 5 7 3 * *}$ & $\mathbf{0 , 8 8 5 * *}$ & 0,140 & & \\
MMG & $\mathbf{0 , 3 6 9 * *}$ & $\mathbf{0 , 2 2 0 *}$ & $-\mathbf{0 , 2 3 0} *$ & 0,099 & & \\
MGP & $\mathbf{0 , 6 1 4} * *$ & $\mathbf{0 , 8 3 8 * *}$ & 0,042 & $\mathbf{0 , 9 1 1 * *}$ & $\mathbf{0 , 3 8 3 * *}$ & \\
POP & $-0,048$ & $\mathbf{- 0 , 5 4 6}^{* *}$ & $-0,080$ & $\mathbf{- 0 , 5 6 4 * *}$ & $-0,045$ & $\mathbf{- 0 , 5 4 5}^{* *}$ \\
\hline
\end{tabular}

(1) PGO, NVP, NGV, NGP, MMG e POP são respectivamente a produtividade de grãos de soja, número de vargens por planta, número de grãos por vagem, número de grãos por planta, massa de mil grãos, massa de grãos por planta e população de plantas; (2) * Significativo a $5 \%$, ** Significativo a $1 \%$.

Fonte: Elaboração dos autores.

Tabela 3. Equações de regressão lineares simples e coeficientes do ajuste entre a produtividade de grãos de soja e os componentes de produção. Selvíria (MS), 2009.

\begin{tabular}{cccc}
\hline \multirow{2}{*}{ Modelo matemático $^{(1)}$} & \multicolumn{3}{c}{ Coeficiente de ajuste $^{(2)}$} \\
\cline { 2 - 4 } & $\mathbf{a}$ & $\mathbf{b}$ & $\mathbf{r}$ \\
\hline PGO $=\mathbf{a}+\mathbf{b} . \mathbf{N V P}$ & $2,006.10^{3}$ & $3,646.10^{* *}$ & $0,651^{* *}$ \\
$\mathbf{P G O}=\mathbf{a} . \mathbf{N G P}^{\mathbf{b}}$ & $3,775.10^{2}$ & $4,944.10^{-1 * *}$ & $0,597^{* *}$ \\
$\mathbf{P G O}=\mathbf{a . M G P}$ & $1,012.10^{3}$ & $4,848.10^{-1 * *}$ & $0,652^{* *}$ \\
$\mathbf{N G P}=\mathbf{a . N V P}$ & 3,051 & $9,208.10^{-1 * *}$ & $0,904^{* *}$ \\
$\mathbf{M G P}=\mathbf{a . N V P}$ & $3,254.10^{-1}$ & $9,924.10^{-1 * *}$ & $0,874^{* *}$ \\
\hline
\end{tabular}

(1) PGO, NVP, NGP, MGP e MMG = são respectivamente, produtividade de grãos de soja, número de vagens por planta, número de grãos por planta, massa de grãos por planta e massa de mil grãos; ${ }^{(2)} * *$ significativo a $1 \%$.

Fonte: Elaboração dos autores. 
$\mathrm{Na}$ análise da regressão linear múltipla da PGO (variável dependente) em função dos componentes de produção (variáveis independentes), o modelo testado (Equação 2) explicou aproximadamente $63,6 \%$ da variação da produtividade de grãos de soja $\left(\mathrm{R}^{2}=0,636^{* *}\right)$. Utilizando-se a referida equação, a partir dos valores médios das variáveis independentes incluídas no modelo, foi possível estimar uma produtividade média de grãos de soja de 4642,4 $\mathrm{kg} \mathrm{ha}^{-1}$. Portanto, esta equação pode perfeitamente ser utilizada para estimar a produtividade de grãos de soja, quando cultivada nas mesmas condições em que está pesquisa foi desenvolvida.

PGO $\left(\mathrm{kg} \mathrm{ha}^{-1}\right)=-6790,6+50,489 . \mathrm{NVP}^{* *}+1109$.

$\mathrm{NGV}^{* *}+18,245 . \mathrm{MMG}^{* *}+$ 0,0125.POP**

Figura 1. Equações de regressão da produtividade de grãos de soja em função do número de vagens por planta (a) e da massa de grãos por planta (b). Selvíria (MS), 2009.

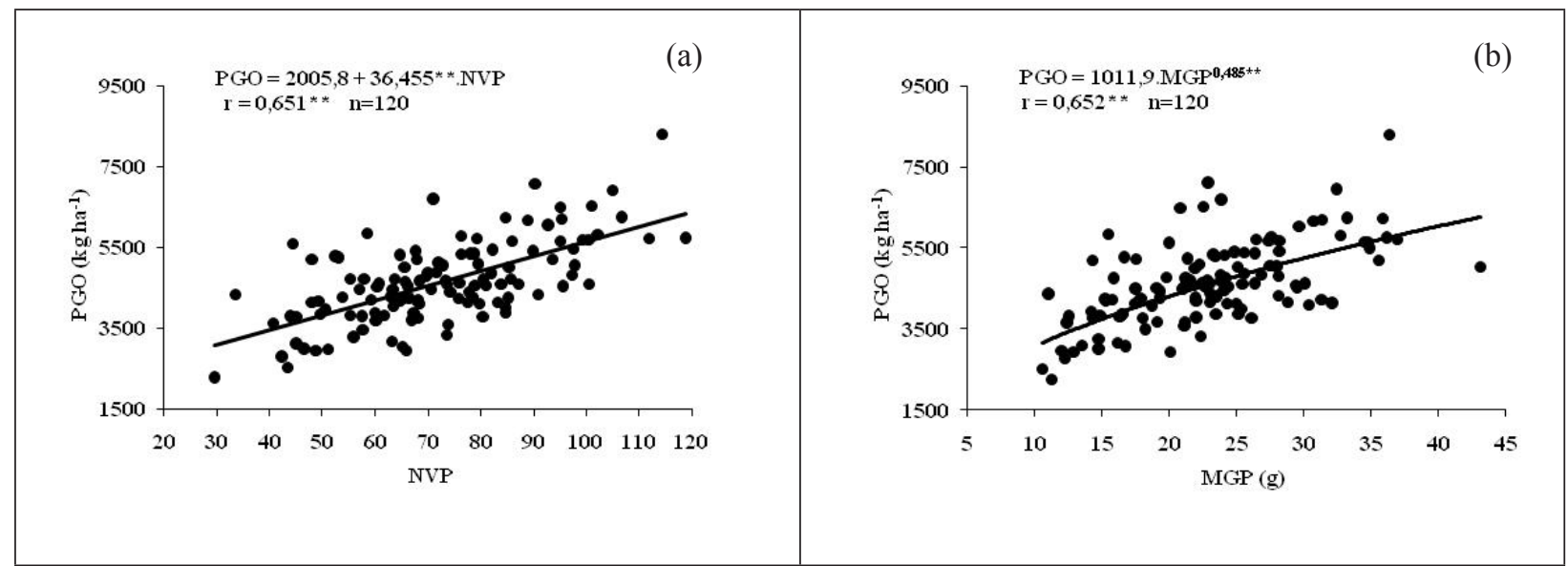

Fonte: Elaboração dos autores.

Com base na Tabela 4, somente os componentes de produção NGV e MMG apresentaram efeito pepita puro, os demais apresentaram dependência espacial, evidenciando que suas distribuições no espaço não foram aleatórias, uma vez que, nos semivariogramas simples, o coeficiente de determinação espacial $\left(\mathrm{r}^{2}\right)$ decresceu na seguinte ordem: (1) MGP (0,928); (2) NVP $(0,889)$; (3) NGP $(0,837)$; (4) PGO $(0,774)$ e (5) POP $(0,697)$. Assim, em relação aos dois primeiros, que tiveram elevados coeficientes de determinação espacial, observou-se o seguinte: MGP, seu $\mathrm{r}^{2}(0,928)$ indicou ser o atributo de melhor ajuste semivariográfico. Em relação ao ADE, o valor observado (60,8\%) foi alto, com alcance de 114,7 metros, com um ajuste do modelo esférico, discordando de Pires (2002), que ajustou o modelo exponencial. Entretanto, o $\mathrm{r}^{2}$ do NVP $\left(\mathrm{r}^{2}=0,889\right)$ indicou ser tal atributo o segundo de melhor ajuste semivariográfico (modelo esférico), com $\mathrm{ADE}$ alto (64,9\%), apresentando alcance da dependência espacial com 99,5 metros, corroborando Pires (2002). Todavia, a PGO apresentou coeficiente de determinação espacial $\left(\mathrm{r}^{2}\right.$ $=0,774$ ) superior ao obtido por Reichert et al. (2008), com 0,708. Contudo, foi inferior ao mencionado por Andreotti et al. (2010) $\left(\mathrm{r}^{2}=0,821\right)$. Por outro lado, o valor da dependência espacial $(88,9 \%)$ foi muito alta, superando os referidos trabalhos. 
Tabela 4. Parâmetros dos semivariogramas simples e cruzados dos componentes de produção e da produtividade de grãos de soja. Selvíria (MS), 2009.

\begin{tabular}{|c|c|c|c|c|c|c|c|c|}
\hline \multirow[b]{2}{*}{ Atributos $^{(1)}$} & \multirow[b]{2}{*}{ Modelo (2) } & \multicolumn{7}{|c|}{ Parâmetros } \\
\hline & & $\begin{array}{c}\text { Efeito } \\
\text { Pepita } \\
\left(C_{0}\right)\end{array}$ & $\begin{array}{c}\text { Patamar } \\
\left(\mathrm{C}_{0}+\mathrm{C}\right)\end{array}$ & $\begin{array}{l}\text { Alcance } \\
(\mathrm{m})\left(\mathbf{A}_{0}\right)\end{array}$ & $\mathbf{r}^{2}$ & $\mathbf{S Q R}^{(3)}$ & $\underset{\text { (4) }}{\mathbf{A D E}}$ & $\begin{array}{c}\text { Classe de } \\
\text { dependência } \\
\text { espacial }\end{array}$ \\
\hline \multicolumn{9}{|c|}{$\gamma(h)$ simples } \\
\hline PGO & $\exp (66)$ & $8,200 \cdot 10^{4}$ & $7,412 \cdot 10^{5}$ & 38,1 & 0,774 & $2,410 \cdot 10^{10}$ & 88,9 & MA \\
\hline NVP & $\operatorname{esf}(222)$ & $1,055.10^{2}$ & $3,004.10^{2}$ & 99,5 & 0,889 & $2,793.10^{3}$ & 64,9 & $\mathrm{AL}$ \\
\hline NGV & epp & $3,750 \cdot 10^{-2}$ & $3,750 \cdot 10^{-2}$ & - & - & - & - & - \\
\hline NGP & $\operatorname{esf}(234)$ & $5,810.10^{2}$ & $1,289.10^{3}$ & 97,1 & 0,837 & $5,261.10^{4}$ & 54,9 & ME \\
\hline \#MMG & epp & $1,374.10^{2}$ & $1,374.10^{2}$ & - & - & - & - & - \\
\hline MGP & $\operatorname{esf}(267)$ & $1,744.10$ & $4,454.10$ & 114,7 & 0,928 & $3,850.10$ & 60,8 & $\mathrm{AL}$ \\
\hline \#POP & $\exp (44)$ & $5,380.10^{8}$ & $1,140.10^{9}$ & 112,5 & 0,697 & $1,320.10^{17}$ & 52,8 & ME \\
\hline \multicolumn{9}{|c|}{$\gamma(h)$ cruzados } \\
\hline PGO=f(NGP) & $\exp (56)$ & $3,500 \cdot 10^{3}$ & $1,392 \cdot 10^{4}$ & 93,0 & 0,597 & $4,180 \cdot 10^{7}$ & 74,9 & $\mathrm{AL}$ \\
\hline PGO $=\mathbf{f}(\mathrm{NVP})$ & esf (183) & $2,600 \cdot 10^{3}$ & $9,720.10^{3}$ & 102,3 & 0,845 & $5,871.10^{6}$ & 73,3 & $\mathrm{AL}$ \\
\hline PGO=f(MGP) & $\operatorname{esf}(311)$ & $1,587.10^{3}$ & $3,545.10^{3}$ & 99,6 & 0,784 & $5,304.10^{5}$ & 55,2 & ME \\
\hline $\mathbf{N G P}=\mathbf{f}(\mathbf{N V P})$ & esf (240) & $1,400.10^{2}$ & $4,938.10^{2}$ & 103,8 & 0,928 & $4,782 \cdot 10^{3}$ & 71,6 & $\mathrm{AL}$ \\
\hline
\end{tabular}

(1) PGO, NVP, NGP, MGP e POP = são respectivamente, produtividade de grãos de soja, número de vagens por planta, número de grãos por planta, massa de grãos por planta e população de plantas; \# trabalhado com o resíduo do atributo; parênteses sucedendo o modelo significa o número de pares no primeiro lag; ${ }^{(2)} \exp =$ exponencial, esf $=$ esférico, epp $=$ efeito pepita puro; ${ }^{(3)} \mathrm{SQR}=\mathrm{soma}$ dos quadrados dos resíduos; ${ }^{(4)} \mathrm{ADE}=$ avaliador da dependência espacial,sendo $\mathrm{ME}=$ média, $\mathrm{AL}=$ alta e MA $=$ muito alta.

Fonte: Elaboração dos autores.

A relação decrescente dos alcances apresentados na Tabela 4 foi: (1) MGP (114,7 m); (2) POP (112,5 m); (3) NVP (99,5 m); (4) NGP (97,1 m) e (5) PGO $(38,1 \mathrm{~m})$. Então, no auxílio a trabalhos futuros, os valores dos alcances a serem utilizados nos pacotes geoestatísticos que alimentarão os pacotes computacionais empregados na agricultura de precisão em geral não deverão ser menores do que $38,1 \mathrm{~m}$, por representarem a distância dentro da qual os valores de um determinado atributo são iguais entre si.

Na Figura 2 são apresentados os mapas de krigagem simples da produtividade (PGO) e de alguns componentes de produção da soja (NVP, MGP e POP). Nas krigagens pode-se observar que nas regiões centro-leste, sudeste e sul ocorreram os mais elevados valores da PGO (4816-6145 kg ha $^{-1}$ ), NVP (74-91) e MGP (24-31 g). Entretanto, para a POP, nessas mesmas regiões ocorreram os menores valores (184921-210295 plantas ha $\left.{ }^{-1}\right)$. Em contrapartida, ocorreu o inverso nas regiões nordeste, norte, noroeste, oeste e sudoeste, isto é, os mais baixos valores da PGO (3043-4372 kg $\mathrm{ha}^{-1}$ ), NVP (50-68) e MGP (15-22 g). Da mesma forma, para a POP, nessas regiões ocorreram os mais elevados valores da densidade populacional (218753-244127 plantas ha-1). Portanto, a PGO apresentou uma distribuição espacial dos seus valores de forma direta com aqueles da NVP e MGP. Contudo, em relação à POP, tal distribuição foi inversa. Especificamente tratando-se da análise da distribuição espacial da produtividade de soja (PGO) com a densidade populacional (POP), os dados do presente estudo corroboraram aqueles de Shimada, Arf e Sá (2000) e Teixeira et al. (2000), que constataram uma correlação inversa entre a produtividade de grãos e a densidade populacional da soja. 
A cokrigagem entre a PGO e NVP (Tabela 4, Figura 3a,b) evidenciou que $84,5 \%$ da variabilidade espacial da PGO foram explicadas pela variabilidade espacial do NVP. Assim, pôdese constatar que onde ocorreram os maiores valores do NVP (Figura 2b) foram mapeados os maiores valores da PGO (Figuras 2 a e $3 b$ ), sendo o inverso verdadeiro. Portanto, do ponto de vista espacial da área pesquisada, nos sítios em que a cultivar de soja BRS-68 Vencedora apresentar o NVP entre 74-91, a PGO estará compreendida entre 4531-6276 kg ha-1. Por outro lado, naqueles onde o NVP estiver entre 50-68, a PGO estará compreendida entre 2204-3949 $\mathrm{kg} \mathrm{ha}{ }^{-1}$.

Figura 2. Mapas de krigagem simples da produtividade de grãos de soja e de alguns componentes de produção. Selvíria (MS), 2009.

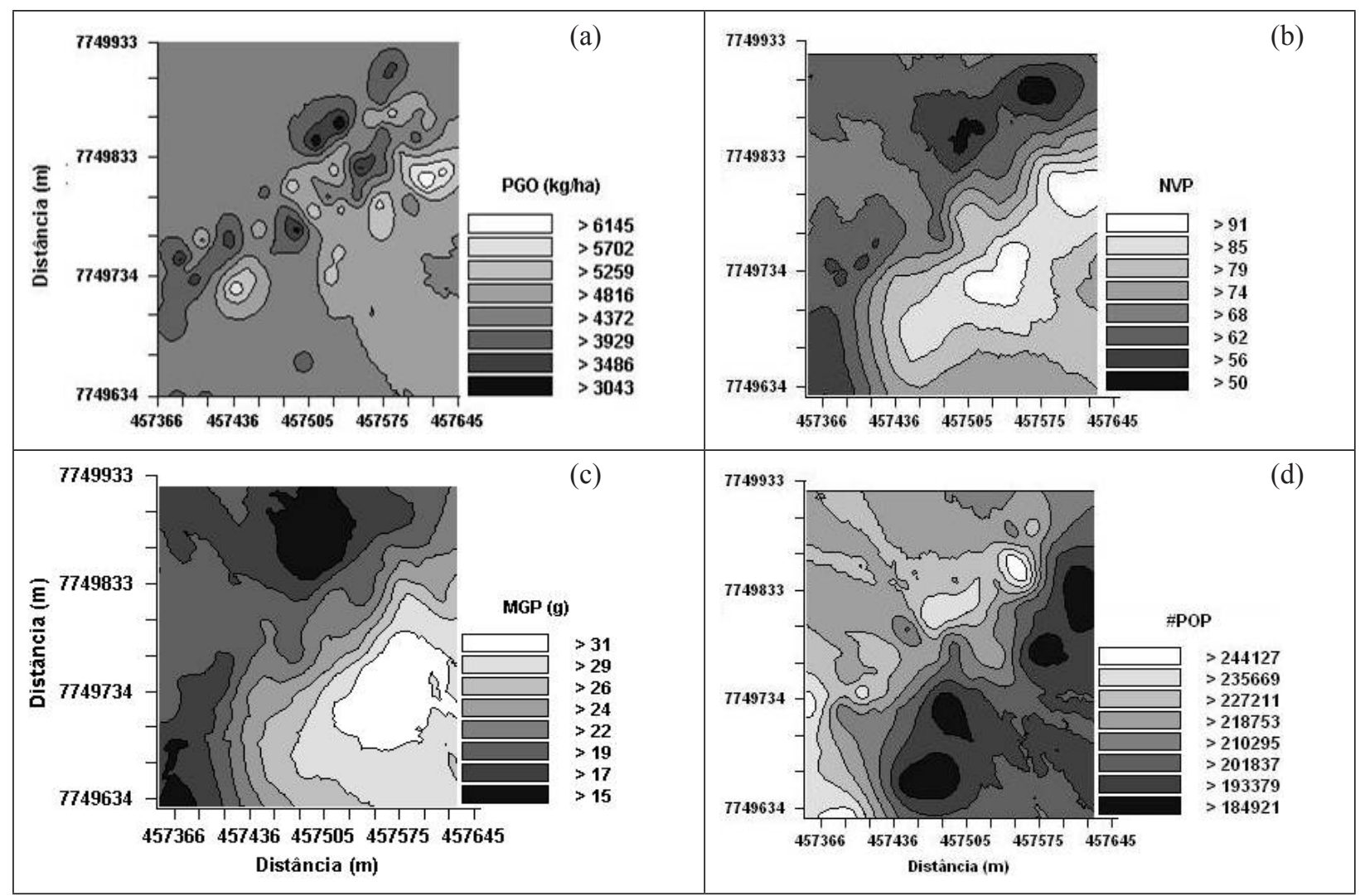

Fonte: Elaboração dos autores.

Da mesma forma, na Figura 3c,d encontram-se o semivariograma cruzado e o mapa de cokrigagem da PGO em função da MGP. Ajustou-se o modelo semivariográfico do tipo exponencial para a referida cokrigagem, com alcance de 99,6 m e dependência média $(\mathrm{ADE}=55,2 \%)$, conforme Tabela 4 . Neste sentido, foi constatado que a variabilidade espacial da MGP explicou 78,4\% da variabilidade espacial da PGO, de maneira que nos sítios onde ocorreram os mais elevados valores da MGP (24-31 g) foram justamente os sítios onde a PGO apresentou os mais elevados valores (4554-6281 $\mathrm{kg} \mathrm{ha}^{-1}$ ), ao passo que nos sítios onde ocorreram os mais baixos valores da MGP (15-22 g) foram justamente os locais onde a PGO apresentou os menores valores (2251-3978 $\mathrm{kg} \mathrm{ha}^{-1}$ ). 
Figura 3. Semivariogramas cruzados $(a, c)$ e mapas de cokrigagens da produtividade de grãos de soja (b,d). Selvíria (MS), 2009.

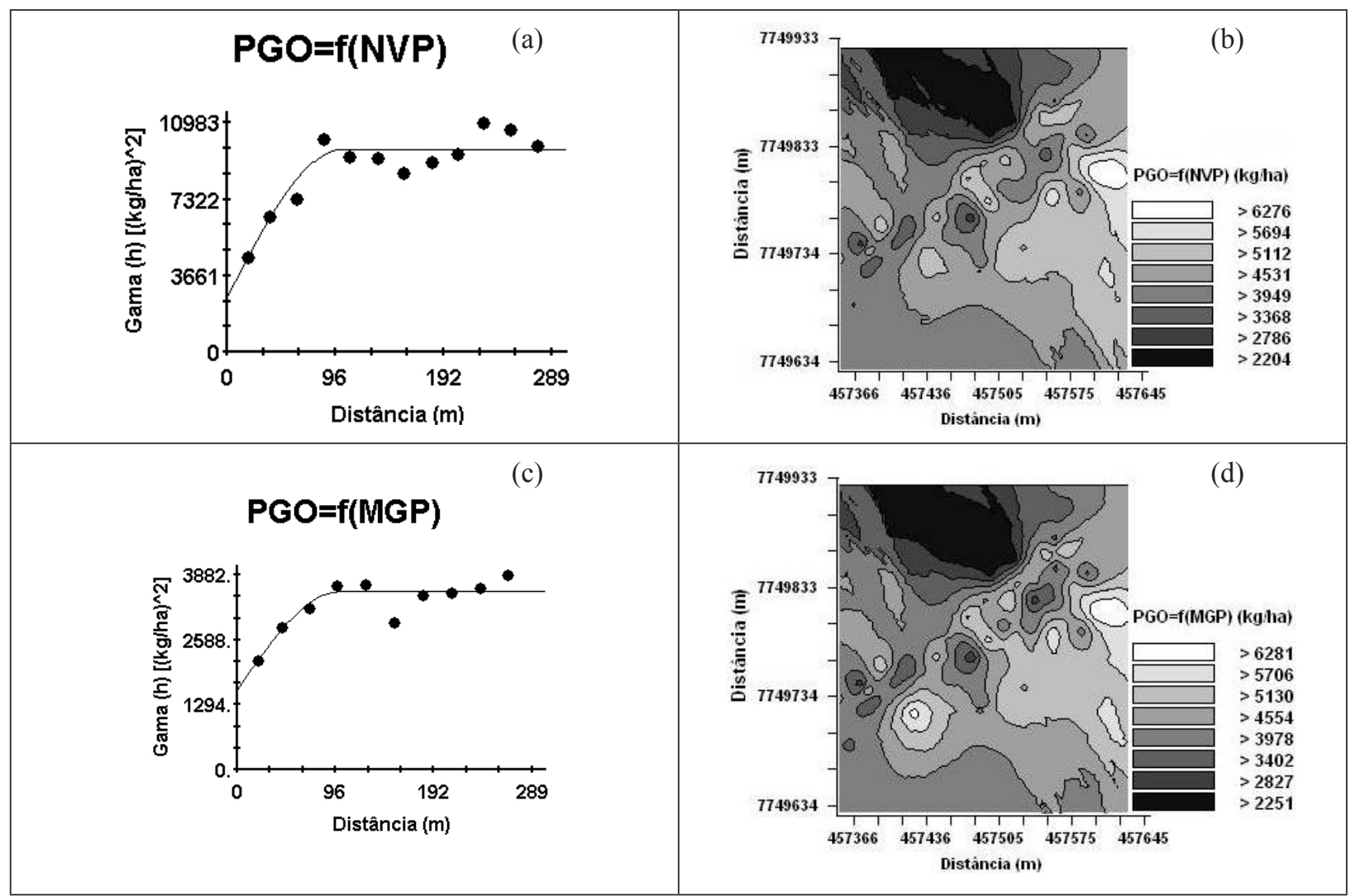

Fonte: Elaboração dos autores.

Portanto, diante da variabilidade espacial, pôde-se constatar que o número de vagens por planta (NVP) e a massa de grãos por planta (MGP), apresentaram-se como bons indicadores da produtividade de grãos de soja (PGO), sugerindo a importância de práticas agrícolas corretas que visem elevar os valores desses componentes de produção, uma vez que ficaram evidenciadas relações diretas com a produtividade de grãos de soja.

\section{Conclusões}

Os valores dos alcances da dependência espacial a serem empregados deverão estar compreendidos entre 38,1 e 114,7 metros. O modelo dos semivariogramas ajustados foi predominantemente o esférico. Do ponto de vista linear e espacial, o número de vagens por planta e a massa de grãos por planta correlacionaram-se de forma direta com a produtividade da soja, demonstrando serem os melhores componentes para estimá-la.

\section{Referências}

AMADO, T. J. C.; PERES, R. B.; COSTA, J. A.; NICOLOSO, R. S.; TEIXEIRA, T. G. A safra recorde analisada pelos mapas de rendimento no RS. Revista Plantio Direto, Passo fundo, v. 14, n. 101, p. 18-23, 2007.

ANDREOTTI, M.; CARVALHO, M. P.; MONTANARI, R.; BASSO, F. C.; PARIZ, C. M.; AZENHA, M. V.; VERCESE, F. Produtividade da soja correlacionada com a porosidade e a densidade de um Latossolo Vermelho do cerrado brasileiro. Ciência Rural, Santa Maria, v. 40, n. 3, p. 520-526, mar. 2010.

CAMBARDELLA, C. A.; MOORMAN, T. B.; NOVAK, J. M. Field-scale variability of soil properties in central Iowa soils. Soil Science Society of American Journal, Madison, v. 58, n. 5, p. 1501-1511, 1994. 
CARPENTIERI-PÍPOLO， V.; GASTALDI， L. F.; PIPOLO, A. E. Correlações fenotípicas entre caracteres quantitativos em soja. Semina: Ciências Agrárias, Londrina, v. 26, n. 1, p. 11-16, 2005.

COMPANHIA NACIONAL DE ABASTECIMENTO CONAB. Acompanhamento da safra brasileira: grãos - décimo levantamento, julho 2010. Brasília: CONAB, 2010. 43 p. Disponível em: <http://www.conab.gov.br/ OlalaCMS/uploads/arquivos/1bcbd827bf80c423c09f4ad ef50fad86.pdf $>$. Acesso em: 01 set. 2010.

COSTA, J. A.; THOMAS, A. L. Potencial de rendimento da soja. Revista Plantio Direto, Passo fundo, v. 11, n. 82, p. 28-32, 2004.

DALCHIAVON, F. C. Aspectos da produtividade do arroz de terras altas irrigado com atributos químicos do solo sob plantio direto. 2010. Dissertação (Mestrado em Agronomia) - Curso de Pós-Graduação em Agronomia. Universidade Estadual Paulista, Ilha Solteira.

DIDONET, A. D.; COSTA, J. G. C. População de plantas e rendimento de grãos em feijoeiro comum de ciclo precoce. Pesquisa Agropecuária Tropical, Goiânia, v. 34, n. 2, p. 105-109, 2004.

EMPRESA BRASILEIRA DE PESQUISA AGROPECUÁRIA - EMBRAPA. Centro Nacional de Pesquisa de Solos (Rio de Janeiro, RJ). Sistema brasileiro de classificação de solos. 2. ed. Rio de Janeiro: Embrapa, 2006. 306 p.

FAHL, J. I.; CAMARGO, M. B. P.; PIZZINATTO, M. A.; BETTI, J. A.; MELO, A. M. T. de; MARIA, I. C.; FURLANI, A. M. C. (Ed.). Instruções agrícolas para as principais culturas. 6 . ed. rev. atual. Campinas: IAC, 1998. $396 \mathrm{p}$.

FARACO, M. A. Qualidade do ajuste de modelos geoestatísticos utilizados na agricultura de precisão. 2006. Dissertação (Mestrado em Engenharia Agrícola) - Universidade Estadual do Oeste do Paraná, Cascavel.

FRASSON, F. R.; MOLIN, J. P. Análise da variabilidade espacial da produtividade de soja utilizando recursos do software R. In: CONGRESSO BRASILEIRO DE AGRICULTURA DE PRECISÃO, 2., 2006, São Pedro. Anais... Piracicaba: USP/ESALQ, 2006. p. 133-137.

GOMES, F. P. Curso de estatística experimental. 14. ed. Piracicaba: FEALQ, 2000. 477 p.

$\mathrm{GS}^{+}$. Geostatistics for environmental sciences. 7. ed. Michigan. Gamma Design Software, 2004. 159 p.

LIMA, C. G. R.; CARVALHO, M. P.; NARIMATSU, K. C. P.; SILVA, M. G.; QUEIROZ, H. A. Atributos físicoquímicos de um Latossolo do cerrado brasileiro e sua relação com características dendrométricas do eucalipto. Revista Brasileira de Ciência do Solo, Viçosa, v. 34, n. 1, p. 163-173, 2010.

LINZMEYER JUNIOR, R. Influência de retardante vegetal e densidade de plantas no crescimento, componentes da produção, produtividade e acamamento na soja. 2006. Dissertação (Mestrado em Agronomia) - Universidade Estadual do Oeste do Paraná, Marechal Cândido Rondon.

MARTINS, M. V.; CARVALHO, M. P.; ANDREOTTI, M.; MONTANARI, R. Correlação linear e espacial entre a produtividade do feijoeiro e atributos físicos de um Latossolo Vermelho Distroférrico de Selvíria, Estado de Mato Grosso do Sul. Acta Scientiarum. Agronomy, Maringá, v. 31, n. 1, p. 147-154, 2009.

MOREIRA, A. A.; LEITE, R. A.; PRADA NETO, I. Cultivo da soja (Glycine max (L.) Merrill) submetido à adubação foliar com cálcio. Perquirere, Patos de Minas, ano 5, jun. 2008.

NAVARRO JÚNIOR, H. M.; COSTA, J. A. Expressão do potencial de rendimentos de cultivares de soja. Pesquisa Agropecuária Brasileira, Brasília, v. 37, n. 3, p. 275-479, 2002.

PIRES, J. L. F. Estimativa do potencial produtivo da soja e variabilidade espacial de área de produção. 2002. Tese (Doutorado em Fitotecnia) - Faculdade de Agronomia. Universidade Federal do Rio Grande do Sul, Porto Alegre.

REICHERT, J. M.; DARIVA, T. A.; REINERT, D. J.; DA SILVA, V. R. Variabilidade espacial de Planossolo e produtividade de soja em várzea sistematizada: análise geostatística e análise de regressão. Ciência Rural, Santa Maria, v. 38, n. 4, p. 981-988, 2008.

ROSA FILHO, G.; CARVALHO, M. P.; ANDREOTTI, M.; MONTANARI, R.; BINOTTI, F. F. S.; GIOIA, M. T. Variabilidade da produtividade da soja em função de atributos físicos de um latossolo vermelho distroférrico sob plantio direto. Revista Brasileira de Ciência do Solo, Viçosa, v. 33, n. 2, p. 283-293, 2009.

SANTOS, M. L.; CARVALHO, M. P.; RAPASSI, R. M. A.; MURAISHI, C. T.; MALLER, A.; MATOS, F. A. Correlação linear e espacial entre produtividade de milho (Zea mays L.) e atributos físicos de um Latossolo Vermelho distroférrico sob plantio direto do Cerrado Brasileiro. Acta Scientiarum. Agronomy, Maringá, v. 28, n. 3, p. 313-321, 2006.

SCHLOTZHAVER, S. D.; LITTELL, R. C. SAS System for elementary statistical analysis. 2. ed. Carolina do Norte: Cary, 1997. 905 p. 
SHAPIRO, S. S.; WILK, M. B. An analysis of variance test for normality: complete samples. Biometrika, Oxford, v. 52, n. 3-4, p. 591-611, 1965.

SHIMADA, M.; ARF, O.; SÁ, M. E. Componentes do rendimento e desenvolvimento do feijoeiro comum de porte ereto sob diferentes densidades populacionais. Bragantia, Campinas, v. 59, n. 2, p. 181-187, 2000.

SILVA, J. M. LIMA, J. S. de S.; MADEIROS, L. B.; VIEIRA, A. de O. Variabilidade espacial da produtividade da soja sob dois sistemas de cultivo no cerrado. Engenharia Ambiental, Espírito Santo do Pinhal, v. 6, n. 2, p. 397-409, 2009.

TEIXEIRA, I. R.; ANDRADE, M. J. B.; CARVALHO, J. G.; MORAIS, A. R.; CORRÊA, J. B. D. Resposta do feijoeiro comum (Phaseolus vulgaris L.cv. Pérola) a diferentes densidades de semeadura e doses de nitrogênio. Ciência e Agrotecnologia, Lavras, v. 24, n. 2, p. 399-408, 2000.

TRANGMAR, B. B.; YOST, R. S.; WADE, M. K.; UEHARA, G. Applications of geostatistics to spatial studies of soil properties. Advances in Agronomy, San Diego, v. 38, n. 1, p. 45-94, 1985.

ZANÃO JÚNIOR, L. A.; LANA, R. M. Q.; CARVALHO-ZANÃO, M. P.; GUIMARÃES, E. C. Variabilidade espacial de atributos químicos em diferentes profundidades em um Latossolo em sistema de plantio direto. Revista Ceres, Viçosa, v. 57, n. 3, p. 429-438, 2010. 